Congreso Latinoamericano de Ciencia Psicológica CLACIP 2014. AACP, Buenos Aires, 2014.

\title{
Cognición Musical y Embodiment: en la búsqueda de la experiencia perdida.
}

\section{Martínez, Isabel Cecilia.}

Cita:

Martínez, Isabel Cecilia (Octubre, 2014). Cognición Musical y Embodiment: en la búsqueda de la experiencia perdida. Congreso Latinoamericano de Ciencia Psicológica CLACIP 2014. AACP, Buenos Aires.

Dirección estable: https://www.aacademica.org/martinez.isabel.cecilia/105 ARK: https://n2t.net/ark:/13683/pGAb/ssC

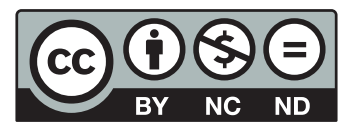


Cognición musical y embodiment: en la búsqueda de la experiencia perdida Isabel Cecilia Martinez isabelceciliamartinez@gmail.com Universidad Nacional de La Plata

Resumen: La experiencia musical es un concepto cuya ontología resulta cuanto menos elusiva. La investigación en cognición musical de los últimos 50 años indagó los procesos que intervienen en la actividad musical desde los paradigmas representacionalista y computacional sin demostrar una preocupación explícita por definir sus alcances. El embodiment, al que hoy adscribe la psicología corporeizada de la música, propone una perspectiva más comprehensiva de experiencia, emergente del constructo mente-cuerpo-entorno y de su carácter multidimensional. Desarrollo. En este trabajo discutimos tópicos de la teoría del embodiment que, entendemos, pueden contribuir a caracterizar el concepto de experiencia musical. Se interrogarán la continuidad mente-cuerpo-entorno y la percepciónacción en la cognición musical, el movimiento como base para la construcción del significado corporeizado en música, y el sentido de sí mismo y del otro en la configuración de los perfiles dinámicos de la experiencia y la cognición musical sentida. Discusión. Se considera que los tópicos discutidos contribuyen a entender el modo en que la dimensión temporal, la atribución de intencionalidad a las acciones propias y de los otros, el desarrollo del pensamiento imaginativo y la construcción del significado se organizan en la experiencia musical. Nos interesa señalar que la revisión de estos aspectos del programa del embodiment constituye un esfuerzo intelectual por definir un concepto de experiencia musical que destaca su carácter multidimensional, corporeizado, intersubjetivo, distribuido y culturalmente situado. 